\title{
Immunogenetics of cytokine genes in parthenium dermatitis: a review
}

\author{
${ }^{1}$ Department of Biochemistry, All India Institute of Medical Sciences, New Delhi, India
}

${ }^{2}$ Department of Dermatology, All India Institute of Medical Sciences, New Delhi, India

\section{KEY WORDS}

parthenium dermatitis; delayed typehypersensitivity; T-lymphocyte; cytokine; immunogenetics; gene polymorphism

\section{Corresponding author}

Alpana Sharma

Department of Biochemistry

All India Institute of Medical Sciences

New Delhi 110029, India

Phone: +91 1126546665

Mobile: +919899061974

Fax: +911126588641

E-mail: dralpanasharma@gmail.com

Doi

10.23822/EurAnnACI.1764-1489.40

\begin{abstract}
Summary
Parthenium dermatitis is a chronic immuno-inflammatory, distressing skin disease, and is mediated by activated T-lymphocyte, which is primarily manifested on the exposed sites of the face, neck, hand and flexures. Parthenium hysterophorus is ubiquitous, hence it is difficult to avoid the aero-allergenic antigen parthenin, responsible for the contact dermatitis. The pathogenesis of parthenium dermatitis is characterized by infiltration of T-lymphocytes into challenged skin sites, and the development of a cutaneous inflammation due to altered regulatory network of pro and anti-inflammatory cytokines. Regulation of inflammatory events perpetuated by cytokines continues to complicate efforts to analyze both the function of individual cytokine and the influence of candidate gene polymorphism on expression and disease severity. The genetic polymorphisms in these cytokines are significantly affecting immunological parameters and, subsequently, modulation and polarization of immune responses. This review has focused mainly on understanding of the mechanisms of genetic susceptibility of cytokine genes in this disease and, further, this process is likely to achieve significant advances in the diagnosis and management of parthenium dermatitis.
\end{abstract}

\section{Introduction}

Parthenium dermatitis is a chronic immuno-inflammatory, distressing skin disease, and is caused by activated T-lymphocytes mediated delayed-type hypersensitivity. The alien weed Parthenium hysterophorus is ubiquitous, and the commonest cause of plant-induced airborne contact dermatitis (ABCD) in India (14). The incidence of parthenium contact dermatitis is increasing considerably year by year, in India and in other parts of the World (5). The parthenium dermatitis reaction is characterized by infiltration of $\mathrm{T}$ lymphocytes into challenged skin sites, and the development of a cutaneous inflammation. Subsequently, over its due course, cutaneous infiltration of various type of immune cells leads to an activation of the cellular immune system, with $\mathrm{T}$ cells and a diverse range of immune-related cytokines and chemokines implicated in pathogenesis $(6,7)$. This feature continues to complicate efforts to analyze both the function of individual cytokines and the influence of cytokine gene polymorphism on gene expression and dermatitis condition; hence, knowledge of immunogenetics of cytokine genes is of utmost importance in this disease.

\section{Epidemiology}

Parthenium dermatitis is an airborne contact dermatitis (ABCD) commonly caused by obnoxius weed Parthenium hysterophorus, which is responsible for more than $30 \%$ of contact dermatitis in India. This weed achieved a status of global significance as responsible for severe human health issues, such as contact dermatitis and respiratory distress. Apart from this, this invasive 
alien weed is considered to be one of the worst plant species for agricultural crops and causes great loss to biodiversity. This aggressive weed at its maturity releases 'parthenin', an airborne antigen to the immediate environment which is a leading cause of airborne contact dermatitis in India $(3,8,9)$. This weed has infested most of rural and waste fields of urban areas, exhibiting the ability to grow prolifically, and in due course invade and adapt to new habitats eventually reducing the number of indigenous plants $(8,10)$. This invasive weed has now become native of more than 20 countries around the World, in five continents $(3,9)$. The pathological condition of parthenium dermatitis, due to various reasons alters the regulatory network of pro and anti-inflammatory cytokines, which leads to cell mediated hypersensitivity (6).

\section{Allergenicity due to Parthenium hysterophorus}

The aero-allergen responsible for the contact dermatitis is parthenin, which is sesquiterpene lactones in nature, profoundly present in the oleoresin fraction of the leaf, stem, flower and to some extent in pollen of Parthenium hysterophorus (figure 1). Sesquiterpene lactones are biologically active plant chemicals identified in many plant families in different geographical regions. P. hysterophorus contains parthenin, hymenin, coronopilin, hysterophorin and tetraneurin $\mathrm{A}$ as major constituents of sesquiterpene lactones $(11,12,13)$. Maishi et al. reported that parthenin, a pungent glycoside, is a major sesquiterpene lactone in P. hysterophorus (14). Parthenin is the major constituent of the antigen causing dermatitis in America, Mexico, West Indies and India; it is replaced by hymenin as an antigen in southern Bolivia and central Argentina, and in one population from Texas. Patients with contact dermatitis to Compositae plants can also have cross reaction to sesquiterpene lactone; containing other non-Compositae plants, however, this cross-reactivity between sesquiterpene lactones does not follow any specific pattern $(15,16)$. Parthenium dermatitis is not reported in some parts of America because of the absence of parthenin in these regions, whereas the dermatitis is severe and causes a major health challenge in Indian subcontinent, where the plant contains large quantity of parthenin antigen $(17,18)$.

\section{Pathogenesis and mechanism of sensitization}

The kinetics of delayed type-hypersensitivity response remains biphasic, and manifests as a contact sensitization phase on initial contact with parthenium antigen, and a later elicitation phase. Parthenium dermatitis is an allergen specific-inflammatory disease, in which parthenium antigen, upon contact sensitization to exposed site of skin, leads to a cell-mediated hypersensitivity immune response, that first induces a refractory phase where probably there is no response, and a subsequent induction phase if persistent antigen exposure further continues to sensitize $(2,19,20)$. Indeed, this immune response is mediated by involvement of a series of cellular and molecular mechanisms. Epidermal antigen presenting Langerhans cells, a family of dendritic cells and other cutaneous dendritic cells, transports the allergen from the skin to regional lymph nodes, where it presents the processed antigen to naïve T-lymphocytes (21). During the sensitization phase, contact allergens stimulate epidermal cells to synthesize and release pro-inflammatory cytokines, such as TNF- $\alpha$ and IL-1, which initiates the activation of LC by expression of costimulatory, adhesion molecule and chemokine receptors. Subsequently, they promote LC migration from the site of $\mathrm{Ag}$ encounter to the area of T-cell priming in the skin (22). Activation of naïve specific T-cell precursors occurs in the regional draining lymph node, upon presentation of haptenated peptides by cutaneous migrating Langerhans cell. Consequently, T-cell proliferation and differentiation occurs, with production of short-lived effector and long-lived memory T-cells. T-cell activation is a highly regulated process, which requires signals at the site of ongoing allergic contact dermatitis, and regional draining lymph nodes (23-26). Upon contact sensitization with antigens, co-stimulatory MHC molecules, like members of B7 family (CD80 and CD86), CD40 and other molecules, are up-regulated on the surface of cutaneous antigen presenting cells (APCs), and keratinocytes that bind with CD28 receptors on the T-cell surface. Antigen presentation in the absence of costimulatory signals leads to $T$ helper cell clonal anergy, a type of immunologic unresponsiveness characterized by reduced cytokine synthesis, a lack of proliferation, and failure to differentiate into effector cells when reencountered with their cognate antigen (22,27-28). The mechanism of signal molecules gene expression in APC and T-cells is pathologically important in amplifying $\mathrm{T}$ lymphocyte-mediated inflammation during contact dermatitis. This alteration of surface molecules on APCs starts incidentally, after contact with antigen and induces T-cell proliferation, cytokine secretion, changes in gene expression, and causes pathogenic skin condition $(29,30)$.

\section{Clinical aspects}

Most of the airborne contact dermatitis starts from the eyelids, primarily, affecting the exposed sites of the face, neck and flexures, that are presented with erythema, blistering and intense pruritus, resulting later in skin thickening, hyper pigmentation and development of a leonine facies. Possibly, unexposed sites may also get involved late in the course of the disease, upon antigen sensitization continued specifically. A seasonal variation has an important role, which is observed with flaring and aggravated dermatitis in the summer, corresponding to the growing season of parthenium plants and remission in winter (31-33). Mixed pattern is a combined form of classical and chronic ac- 
tinic dermatitis, which manifests as scattered infiltrated scaly papules over exposed site. Classical pattern of dermatitis changes to photodermatitis and photosensitive pruritic lichenified eruption, which presents with discrete, violaceous papules and plaques which develops after many years without seasonal variation (34). Exacerbation of parthenium dermatitis occurs mainly in summer and rainy seasons because of profuse growth of weed parthenium plants, and is prevalent in winter season in southern India during the months of September, October and November, which is maybe due to the increased growth of parthenium following the North-East monsoon showers, as reported by Lakshmi C. $(35,36)$. The skin of the upper eyelids, the retro-auricular and submental areas, which are spared in photodermatitis, are involved in parthenium dermatitis. The dermatitis can become generalized to produce an erythroderma (37). In a recent study, parthenium dermatitis severity scores (PDSS) is found to be a useful tool in determining the severity of the disease, and may be used by clinicians for appropriate scoring of the clinical severity of parthenium dermatitis and monitoring the disease response to therapy. The severity of parthenium-induced dermatitis in sensitized patients depends on the degree of contact hypersensitivity at that time, quantity of antigen, and areas in contact with the patients (38). The effect of seasonal variation also plays an important role on degree of contact hypersensitivity, as the sensitivity to parthenium allergen increases more in summer than winter (39).

\section{Treatment and management}

It has been established that corticosteroids are the mainstay of recommended treatment in the parthenium induced contact dermatitis, especially in severe cases. Topical steroids can be used for mild to moderate disease, while severe / extensive dermatitis will require systemic steroids (19,35). Azathioprine acts as an inflammatory cell inhibitor, corticosteroid-sparing agent, has an immunosuppressive and anti-inflammatory effect, and plays an important role in management of chronic parthenium dermatitis, as reported by Verma KK et al. (2006) $(40,41)$.

Azathioprine or other adjuvants like methotrexate or cyclosporine can be used in maintenance doses, and suppress the delayed type hypersensitivity reaction. Along with medication, protection can be given by covering the exposed parts, removal of the patient from the contaminated environment, desensitization methods. Although, complete allergens avoidance from the environment is almost impossible for sensitized patients (42-44). Cyclosporine is also an immunosuppressive with potent anti-inflammatory properties, and has been reported to be effective in the severe condition of parthenium dermatitis. It produces a swift response, and also spares from the side effects of systemic corticosteroid treatment. It suppresses the delayed hypersensitivity reaction, as well as the late phase reaction of type I hypersensitivity (35).
Parthenium hysterophorus is ubiquitous, hence it is difficult to avoid the aero-allergens; the only option is to reduce the quantity of antigen exposure to which patient is already exposed. Exposure to sunlight is also distressing to the parthenium patients, as it exaggerates the disease. Covering of exposed parts of skin and using sunscreen lotions that may serve as barrier creams, can slow down the penetration of the antigens into the sensitized skin (45).

\section{Immune responses in parthenium dermatitis}

Parthenium dermatitis is better known as an immuno-modulatory dermatitis, which upon contact sensitization with antigen leads to a cell mediated immune response with the kinetics of sensitization, and an elicitation phase followed by stimulation of naïve $\mathrm{T}$ cells. Furthermore, during the sensitization phase, contact allergens stimulate epidermal cells to synthesize and release pro-inflammatory cytokines such as TNF- $\alpha$ and IL-1, which in turn promote Langerhans cells migration from the skin. The challenged skin sites reaction serves as a repository for proliferation of activated T-lymphocytes, that eventually produce effectors and memory cells which lead to development of cutaneous inflammation, and endows with rapid and specific responses upon re-exposure of sensitized antigens $(20,46,47)$. The mechanism of pathogenesis involves a complex, intricate regulatory network of inflammation mediators, T regulatory and pro and anti-inflammatory cytokines released by various immune modulator cells (48). In normal condition, these cytokines cross regulate each other, and a balance exists between these modulatory molecules (49). Depending upon the kind of allergen encounter and cytokine milieu, polarization of naïve T-helper cells happens in direction of TH1, TH17 or TH2 cells type immune responses $(50,51,30)$. During the entire inflammatory reaction, cytokines released by various immune cells function as communicators between different cells. Altogether, the type of immune response is determined and directed by all the existing factors after antigen sensitization $(52,53)$.

$T$ reg cells contribute to the control of allergen-specific immune responses through multiple mechanisms: suppression of antigen-presenting cells that support the generation of TH1 and TH2 effector cells, and remodeling of resident tissue cells. Immune system dysregulation and $\mathrm{T}$ helper cells play a key role in eliciting and maintaining inflammation in the skin during contact sensitization with antigen. Mechanism of enhancing skin inflammation by aero-antigen includes expansion and migration of skin-homing $\mathrm{T}$ cells, and inhibition of $\mathrm{T}$ reg cell immunosuppressive function (54).

\section{Cytokine profiling in parthenium dermatitis}

The immune response is regulated by a highly complex and intricate network of control elements; a dynamic balance ex- 
ists between proinflammatory cytokines and anti-inflammatory components $(48,55)$. Polarization of T-helper (TH) lymphocytes into functional $\mathrm{TH} 1$ and $\mathrm{TH} 2$ subsets is one of the main factors that determine the direction of the balance between pro- and anti-inflammatory cytokines $(50,56)$. A number of cytokines, known collectively as pro-inflammatory cytokines because they accelerate inflammation, also regulate inflammatory reactions, either directly or by their ability to induce the synthesis of cellular adhesion molecules or other cytokines in certain cell types. Regulation of T-cell activation by the anti-inflammatory cytokines is a crucial early control element in the process of inflammation of skin $(51,57)$. Our previous studies on parthenium dermatitis showed elevated circulating levels of proinflammatory cytokines such as IFN- $\gamma$, IL-2, TNF- $\alpha$, IL6, IL-8, IL-17, and lower levels of anti-inflammatory cytokines such as IL-10 and TGF- $\beta$ in patients compared with controls, Akhtar et al. (2010). This suggests that the lower circulating level of IL-10 and TGF- $\beta$ (an anti-inflammatory and immunosuppressive cytokine) might be insufficient to counter- regulate the proinflammatory signals which lead to a hypersensitivity immune response $(2,4)$.

\section{Immuno-genetics of cytokine genes polymorphisms}

There are a number of factors which affect the levels of cytokine production among different individuals. These include gene transcription stability, post translation modification, protein intracellular stability, and the export of cytokine to the extracellular environment. Besides this, the genetic polymorphism of these cytokine genes in gene regulatory and protein coding regions majorly affects cytokine production in different individuals $(7,58)$. The pathogenesis of parthenium dermatitis is considered to be an immunologically mediated process. Due to various reasons, altered regulatory network of pro and anti-inflammatory cytokines leads to cell mediated hypersensitivity. Regulation of inflammation events perpetuated by cytokines acts in a highly complex coordinated network, in which they induce or repress their own synthesis as well as that of other cytokines and cytokine receptors. This feature continues to complicate efforts to analyze both the function of individual cytokines and the influence of cytokine gene polymorphism on gene expression and disease $(59,60)$.

Based on various parameters, previous reports suggested that parthenium dermatitis pathogenesis involves cell-mediated hypersensitivity immune response, and happens due to imbalance in various pro and anti- inflammatory and $\mathrm{T}$ reg cell cytokines. Among the number of risk factors leading to allergy, the interaction of genetics of an individual with environment is one of the affecting significant parameters. The functional genetic alterations in structure of these cytokine genes are among a number of factors which influence the variation in systemic cytokine levels. The genetic polymorphisms in these cytokine genes are significantly affecting parameters, which influence the inter-individual differences in cytokine levels and determine the balance between these, and direct the kind of human immune response. In many diseases, these polymorphic cytokine gene regions have been found as susceptibility factors $(61,62)$.

In a recently published study, we have analyzed IFN $-\gamma(+) 874$ $\mathrm{A}>\mathrm{T}$ and IL-10 (-) $1082 \mathrm{G}>\mathrm{A}$ and $(-) 819 \mathrm{C}>\mathrm{T}$ single nucleotide polymorphisms in parthenium dermatitis cases vs. control subjects. The study showed that the IFN- $\gamma(+) 874$ A > T SNP genetically does not justify the high serum levels of IFN- $\gamma$ in parthenium dermatitis patients in comparison to healthy controls, whereas the lower producing genotypes due to IL-10 (-) $1082 \mathrm{G}>\mathrm{A}$ and (-) $819 \mathrm{C}>\mathrm{T}$ SNPs remain in step with the prevalence of low serum IL-10 in parthenium patients, and these genotypes genetically predispose to this disease. The intermediate IL-10 producing genotypes due to these SNPs in IL-10 gene, provide resistance to the carriers of these genotypes for not developing the disease $(7,63)$ (table I).

In earlier reports, altered levels of TNF- $\alpha$ have been found involved in pathogenesis of psoriasis. There are numerous polymorphisms found in TNF- $\alpha$ promoter region, which might modulate TNF- $\alpha$ expression. The single nucleotide polymorphism at position (-) $308 \mathrm{G} / \mathrm{A}$ has been found to be a functional and genetic predisposition to various diseases, like liver cirrhosis, rheumatoid arthritis, inflammatory bowel disease, etc. This polymorphism has also been reported in asthma and other allergic diseases like occupational chronic irritant contact dermatitis (CICD) and psoriasis (64-66).

The prevalence of high TH1 cytokines (IFN- $\gamma$, IL-2, pro- inflammatory IL-6, IL-8, IL-17, TNF- $\alpha$ ) and declined levels of TH2 cytokines (IL-10) and T reg cytokine (TGF- $\beta 1$ ) reported by Akhtar et al., suggests that an insufficient amount of anti-inflammatory and immunosuppressive cytokines might unable to downregulate the TH1 cytokines. Thereby, their levels might remain high in patients (2). Khatri et al. (2013) found that the SNPs IFN- $\gamma(+) 874 \mathrm{~A}>\mathrm{T}$ and TNF- $\alpha(-) 308 \mathrm{G}>\mathrm{A}$ are not associated with the disease. Therefore, high serum levels of IFN- $\gamma$ and TNF- $\alpha$ in patients are not genetically in step with the studied SNPs in these genes (67). The alleles at both the loci did not lead to any association with the disease, but the low IL-10 producing genotypes such as AA and TT, created a 2.01 and 3.45 times higher risk respectively for patients for developing the parthenium dermatitis, whereas the intermediate IL-10 producing GA and CT genotypes at these loci provided 54\% and 67\% resistance respectively to the individuals for not developing the disease. The low TGF- $\beta 1$ producing genotypes $\mathrm{CC}$ at this locus were prevalent in parthenium patients compared to controls, but upon statistical comparison the p-value remained little far from value of significance. In conclusion, concordance between 
Table I - Cytokine and their genetic polymorphism studies in parthenium dermatitis.

\begin{tabular}{lll}
\hline $\begin{array}{l}\text { Source and related } \\
\text { parameter }\end{array}$ & $\begin{array}{l}\text { Significance } \\
\text { patients } \boldsymbol{v} \text { s. control }\end{array}$ & References \\
\hline $\begin{array}{l}\text { TH1 type cytokine } \\
\text { IL-2, IFN- } \gamma\end{array}$ & significantly increased compared to control & \\
\hline $\begin{array}{l}\text { TH17 type cytokine } \\
\text { IL-17 }\end{array}$ & significantly increased compared to control & Akhtar N et al. (2010) Contact Dermatitis \\
\hline $\begin{array}{l}\text { TH2 type cytokine } \\
\text { IL-4, IL-10 }\end{array}$ & only IL-10 significantly decreased & \\
\hline $\begin{array}{l}\text { T reg type cytokine } \\
\text { TGF- } \beta\end{array}$ & significantly decreased & Akhtar N et al. (2010) Clin Chem Acta \\
\hline IL-6, IL-8, TNF- $\alpha$ & significantly increased compared to control & Akhtar N et al. (2010) Contact Dermatitis \\
\hline Genetic polymorphism & Risk assessment & \\
\hline IFN- $\gamma(+) 874$ A $>$ T & no association & Khatri R et al. (2011) BJD \\
\hline IL-10 (-) $1082 \mathrm{G}>\mathrm{A}$ and (-) $819 \mathrm{C}>\mathrm{T}$ & 2.01 and 3.45 times more risk & Khatri R et al. (2014) IJD \\
\hline TNF- $\alpha(-) 308 \mathrm{G}>\mathrm{A}$ & no association & unpublished \\
\hline TGF- $\beta 1(-) 509 \mathrm{C}>\mathrm{T}$ & associated & unpublished \\
\hline IL-4 (-) $590 \mathrm{C}>\mathrm{T}$ & no association &
\end{tabular}

low TGF- $\beta 1$ producing CC genotypes along with low serum levels of TGF- $\beta 1$, suggested the association of this locus with the disease, which needs further validation in larger sample size.

\section{Conclusions}

Several studies to date have been reported to analyze the influence of gene polymorphisms on various cytokine gene expression and disease conditions. Cytokines are communicating molecules between cells of immune system, and express a critical role in polarization, amplification and modulation of immune responses, and determine which effector mechanisms are to be employed in response to immune challenge. Our studies on parthenium dermatitis suggest the prevalence of high serum IFN- $\gamma$ in patients, but the IFN- $\gamma(+) 874 \mathrm{~A}>\mathrm{T}$ transition genetically does not contribute to the parthenium dermatitis. The small sample size may be one of the limitations, and a larger cohort study may provide conclusive association of genetic predisposition of IFN gene. In contrast, low IL-10-producing genotypes in patients is associated with a high prevalence due to IL-10 (-) $1082 \mathrm{G}>\mathrm{A}$, and (-) $819 \mathrm{C}>\mathrm{T}$ polymorphisms. The concerned IL-10 genotypes at these loci show a strong genetic predisposition to parthenium dermatitis in Indian cohort, and function as risk factors. Mostly, healthy individuals possessed intermediate IL-10 producing GA and CT genotypes with a statistically significant difference from dermatitis patients. In our recent study, no genetic endowment
Figure 1 - Parthenium hysterophorus. A, leaves; $B$, mature plant; $C$, flowers; and D, chemical structure of parthenin antigen. Figure from our published paper.

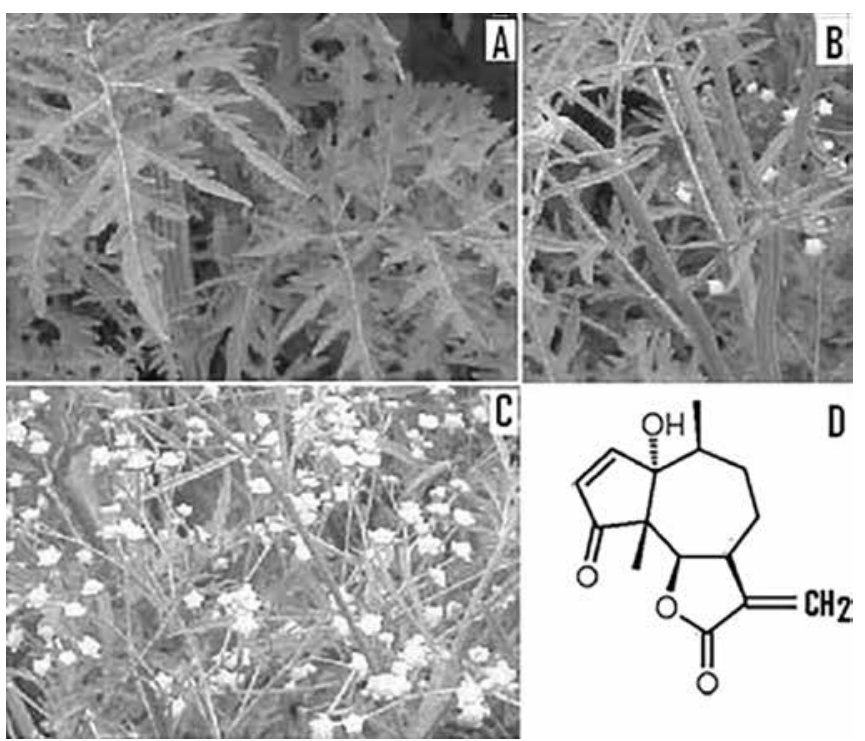

of TNF- $\alpha$ (-) $308 \mathrm{G}>$ A polymorphism was found in pathogenesis / susceptibility associated to parthenium dermatitis, even with high level of TNF- $\alpha$. A thorough prospective analysis in a higher number of subjects is required to understand the role of 
TNF- $\alpha$ genetic variation in pathogenesis of parthenium disease. The reports in this review suggest that even though IFN- $\gamma$ and TNF- $\alpha$ gene polymorphisms are not associated with parthenium dermatitis, genotyping marker in disease condition is considered to be potentially important. Thus, this review enlightens the important role of immunogenetics in parthenium dermatitis. Further continued advances in molecular genetics and in high-throughput of genotyping of cytokine genes are likely to achieve significant advances in the diagnosis and management of parthenium dermatitis.

\section{Conflict of interest}

The authors declare that they have no conflict of interest.

\section{References}

1. Verma K K, Mahesh R, Srivastava P, Ramam M, Mukhopadhyaya A K. Azathioprine versus betamethasone for the treatment of parthenium dermatitis: a randomized controlled study. Indian J Dermatol Venereol Leprol 2008; 74:453-7.

2. Akhtar N, Verma KK, Sharma A. Study of pro and anti-inflammatory cytokine profile in the patients with parthenium dermatitis. Contact Dermatitis 2010; 63:203-8.

3. Towers G H, Mitchell J C. The current status of the weed Parthenium hysterophorus $\mathrm{L}$. as a cause of allergic contact dermatitis. Contact Dermatitis 1983; 9:465-9.

4. Akhtar N, Satyam A, Anand V, Verma KK, Khatri R, Sharma A. Dysregulation of TH type cytokines in the patients of parthenium induced contact dermatitis. Clin Chimica Acta 2010; 411:2024-8.

5. Lonkar A, Mitchell JC, Calnan CD. Contact dermatitis from Parthenium hysterophorus. Trans St Johns Hosp Dermatol Soc 1974; 60:43-53.

6. Kimber I, Dearman R J. Allergic contact dermatitis: the cellular effectors. Contact Dermatitis 2002; 46:1-5.

7. Khatri R, Mukhopadhyay K, Verma KK, Sethuraman G, Sharma A. Genetic predisposition to parthenium dermatitis in an Indian cohort due to lower-producing genotypes of interleukin-10 (-) $1082 \mathrm{G}>\mathrm{A}$ and (-) $819 \mathrm{C}>\mathrm{T}$ loci but no association with interferon-g (+) 874 A>T locus. Br J Dermatol 2011; 165:115-22.

8. Seema Patel. Harmful and beneficial aspects of Parthenium hysterophorus: an update. 3 Biotech 2011; 1:1-9.

9. Gajanan G, Fernandes N. Parthenium allergy in Indian population: clinical significance. Journal of Evidence based Medicine and Healthcare 2015; 2(41):7109-17.

10. Singh RK, Kumar S, Kumar S, Kumar A. Development of parthenium based activated carbon and its utilization for adsorptive removal of p-cresol from aqueous solution. J Haz Mat 2008; 155:523-35.

11. Neerman ME. Sesquiterpene lactones: a diverse class of compounds found in essential oils possessing antibacterial and antifungal properties. Int J Aromatherapy 2003; 13:114-20.

12. Rao PV, Mangala A, Towers GH, Rodriguez E. Immunological activity of parthenin and its diastereomer in persons sensitized by Parthenium hysterophorus L. Contact Dermatitis 1978; 4:199-03.

13. De La Fuente JR, Novara L, Alarcon SR, Diaz OJ, Uriburu ML, Sosa VE. Chemotaxonomy of parthenium: P. hysterophorus-P. glomeratum. Phytochemistry 1997; 45:1185-8.
14. Maishi AI, Ali PKS, Chaghtai SA, Khan G. A proving of Parthenium hysterophorus, L. Brit Homoeopath J 1998; 87:17-21.

15. Picman AK, Towers GH. Sesquiterpene Lactones in various populations of Parthenium hysterophorus. Biochemical Syst Ecol 1982; 10:145-53.

16. Picman AK, Picman J, Towers GH. Cross-reactivity between sesquiterpene lactones and parthenin in parthenin-sensitized guinea pigs. Contact Dermatitis 1982; 8:294-01.

17. Lonkar A, Nagasampagi BA, Narayanan CR, Landge AB, Sawaikar DD. An antigen from Parthenium hysterophorus Linn. Contact Dermatitis 1976; 2:151-4.

18. Towers GH, Mitchell JC, Rodriguez E. Biology and chemistry of Parthenium hysterophorus L. a problem weed in India. J Sci Ind Res 1997; 36:672-84.

19. Vinod K Sharma, Parul Verma. Parthenium dermatitis in India: past, present and future Indian J Dermatol Venereol Leprol 2012; 78(5):560-8.

20. Rìos J L, Bas E, Recio MC. Effects of natural products on contact dermatitis. Curr Med Chem Anti-Inflammattory and Anti-Allergy Agents 2005; 4:65-80.

21. Mark C. Udey. Epidermal Langerhans cells tune skin reactivity to contact allergens. J Clin Invest 2012; 122(5):1602-5.

22. Mueller DL, Jenkins MK, Schwartz RH. Clonal expansion versus functional clonal inactivation: a costimulatory signalling pathway determines the outcome of $\mathrm{T}$ cell antigen receptor occupancy. Annu Rev Immunol 1989; 7:445-80.

23. Walsh KP, Mills KH. Dendritic cells and other innate determinants of T helper cell polarisation. Trends Immunol 2013; 34:521-30.

24. Alvarez D, Vollmann EH, Von Andrian UH. Mechanisms and consequences of dendritic cell migration. Immunity 2008; 29:325-42.

25. Kripke ML, Munn CG, Jeevan A, Tang JM, Bucana C. Evidence that cutaneous antigen-presenting cells migrate to regional lymph nodes during contact sensitization. J Immunol 1990; 145:2833-8.

26. Schmidt JD, Ahlström MG, Johansen JD, Dyring-Andersen B, Agerbeck C, Nielsen MM et al. Rapid allergen-induced interleukin- 17 and interferon- $\gamma$ secretion by skin resident memory CD8+ T cells. Contact Dermatitis 2017; 76(4):218-27.

27. Wakem P, Burns RP Jr, Ramirez F, Zlotnick D, Ferbel B, Haidaris CG et al. Allergens and irritants transcriptionally upregulate CD80 gene expression in human keratinocytes. J Invest Dermatol 2000; 114(6):1085-92.

28. Azuma M, Ito D, Yagita H, Okumura K, Phillips JH, Lanier LL et al. B70 antigen is a second ligand for CTLA-4 and CD28. Nature 1993; 366(6450):76-9.

29. Mann ER, Smith KM, Bernardo D, Al-Hassi HO, Knight SC, Hart AL. Review: skin and the Immune System. J Clin Exp Dermatol Res 2012; S2:003. doi:10.4172/2155-9554.S2-003.

30. Zhu J, Paul WE. CD4 T cells: fates, functions, and faults. Blood 2008; 112:1557-69.

31. Agarwal KK, Nath AK, Jaisankar TJ, D’Souza M. Parthenium dermatitis presenting as erythroderma. Contact Dermatitis 2008; 59:182-3

32. Sethuraman G, Bansal A, Sharma VK and Verma KK. Seborrhoeic pattern of parthenium dermatitis. Contact Dermatitis 2008; 58:372-4

33. Shenoi SD, Srinivas CR. Changing clinical patterns of parthenium dermatitis. Contact Dermatitis 1997; 37:128.

34. Sharma VK, Sahoo B. Prurigo-nodularis-like lesions in parthenium dermatitis. Contact Dermatitis 2000; 42:235-48. 
35. Lakshmi C, Srinivas CR, Jayaraman A. Ciclosporin in parthenium dermatitis - a report of 2 cases. Contact Dermatitis 2008; 59:245-8.

36. Lakshmi C, Srinivas CR, Pillai SB, Shanthakumari S. Parthenium dermatitis manifesting clinically as polymorphic light eruption and prurigo nodularis-like lesions with vasculitis-like picture on histopathology. Indian Dermatol Online J 2011; 2(2):97-100.

37. Sharma VK. Patch testing with the European standard series and compositae extracts in patients with airborne contact dermatitis. Contact Dermatitis 2001; 44:49-50.

38. Verma KK, Bansal A, Bhari N, Sethuraman G. Parthenium dermatitis severity score to assess clinical severity of disease. Indian J Dermatol 2017; 62(1):85-7.

39. Verma KK, Singh S, Kumar P, Pandey RM. Seasonal variation in contact hypersensitivity to parthenium in patients of parthenium dermatitis. Indian J Dermatol 2016; 61(1):53-6.

40. Verma KK, Bansal A, Sethuraman G. Parthenium dermatitis treated with azathioprine weekly pulse doses. Indian J Dermatol Venereol Leprol 2006; 72:24-7.

41. Srinivas CR, Balachandran C, Shenoi SD, Acharya S. Azathioprine in the treatment of parthenium dermatitis. Br J Dermatol 1991; 124:394-5.

42. Sharma VK, Bhat R, Sethuraman G, Manchanda Y. Treatment of parthenium dermatitis with methotrexate. Contact Dermatitis 2007; 57:118-9.

43. Verma KK, Mahesh R, Srivastava P, Ramam M, Mukhopadhyaya AK. Azathioprine versus betamethasone for the treatment of parthenium dermatitis: a randomized controlled study. Indian J Dermatol Venereol Leprol 2008; 74:453-7.

44. Verma KK, Sethuraman G, Kalavani M. Weekly azathioprine pulse versus daily azathioprine in the treatment of parthenium dermatitis: a non-inferiority randomized controlled study. Indian J Dermatol Venereol Leprol 2015; 81:251-6.

45. Andersson M, Andersson P, Pipkorn U. Topical glucocorticosteroids and allergen-induced increase in nasal reactivity: relationship between treatment time and inhibitory effect. J Allergy Clin Immunol 1988; 82:1019-26.

46. Werfel T, Allam JP, Biedermann T, Eyerich K, Gilles S, Guttman-Yassky E, et al. Cellular and molecular immunologic mechanisms in patients with atopic dermatitis. J Allergy Clin Immunol 2016; 138(2):336-49.

47. Kimber I, Dearman R J. Allergic contact dermatitis: the cellular effectors. Contact Dermatitis 2002; 46:1-5.

48. Kasai T, Inada K, Takakuwa T, Yamada Y, Inoue Y, Shimamura T et al. Anti-inflammatory cytokine levels in patients with septic shock. Res Commun Mol Pathol Pharmacol 1997; 98:34-42.

49. Steven M, Opal, Vera A, De Palo. Anti-inflammatory cytokines. Chest 2000; 117:1162-72.

50. Kelso A. TH1 and TH2 subsets: paradigms lost? Immunol Today 1995; 16:374-9.

51. Zhu J, Paul WE. Peripheral CD4 T cell differentiation regulated by networks of cytokines and transcription factors. Immunol Rev 2010; 238(1):247-62.

52. Larche M, Akdis CA, Valenta R. Immunological mechanisms of allergen-specific immunotherapy. Nat Rev Immunol 2006; 6:761-71.

53. Akdis M. Healthy immune response to allergens: T regulatory cells and more. Curr Opin Immunol 2006; 18:738-44.
54. Akdis M, Blaser K, Akdis CA. T regulatory cells in allergy: novel concepts in the pathogenesis, prevention, and treatment of allergic diseases. J Allergy Clin Immunol 2005; 116:961-8.

55. Sharma A, Rajappa M, Saxena A, Sharma M. Cytokine profile in Indian women with cervical intraepithelial neoplasia and cancer cervix. Int J Gynecol Cancer 2007; 17:879-85.

56. Muraille E, Leo O. Revisiting the TH1/TH2 paradigm. Scand J Immunol 1998; 47:1-9.

57. Kurts C. TH17 cells: a third subset of CD4+ T effector cells involved in organ specific autoimmunity. Nephrol Dial Transplant 2008; 23(3):816-9.

58. Reich K, Mössner R, König IR, Westphal G, Ziegler A, Neumann Ch. Promoter polymorphisms of the genes encoding tumor necrosis factor-alpha and interleukin-1beta are associated with different subtypes of psoriasis characterized by early and late disease onset. J Invest Dermatol 2002; 118 (1):155-63.

59. Grabbe S, Schwarz T. Immunoregulatory mechanisms involved in elicitation of allergic contact hypersensitivity. Immunol Today 1998; 19(1):37-44.

60. Barker JN, Mitra RS, Griffiths CE, Dixit VM, Nickoloff BJ. Keratinocytes as initiators of inflammation. Lancet 1991; 337(8735):211-4.

61. Hussein YM, Ahmad AS, Ibrahem MM, El Tarhouny SA, Shalaby SM, Elshal AS et al. Interferon gamma gene polymorphism as a biochemical marker in Egyptian atopic patients. J Investig Allergol Clin Immunol 2009; 19(4):292-8.

62. de Jongh CM, John SM, Bruynzeel DP, Calkoen F, van Dijk FJ, Khrenova L et al. Cytokine gene polymorphisms and susceptibility to chronic irritant contact dermatitis. Contact Dermatitis 2008; 58:269-77.

63. Reuss E, Fimmers R, Kruger A, Becker C, Rittner C, Hohler T. Differential regulation of interleukin- 10 production by genetic and environmental factors: a twin study. Genes Immun 2002; 3:407-13.

64. Schottelius AJG, Moldawer LL, Dinarello CA, Asadullah K, Sterry W, Edwards CK. Biology of tumor necrosis factor- $\alpha$ - implications for psoriasis. Exp Dermatol 2004; 13:193.

65. Baran W, Szepietowski JC, Mazur G, Baran E. A -308 promoter polymorphism of tumor necrosis factor alpha gene does not associate with the susceptibility to psoriasis vulgaris. No difference either between psoriasis type-I and type-II patient. Acta Dermatoven APA 2006; 15:113-8.

66. Cherkashina II, SIu Nikulina, Logvinenko NI, Voevoda MI, Maksimov VN, Liberdovskaia ED. The specific features of TNF-alpha gene polymorphism in asthmatic patients and their relatives. Probl Tuberk Bolezn Legk 2009; 51-6.

67. Khatri R, Akhtar N, Mukhopadhyay K, Verma KK, Sethuraman G, Sharma A. Genetic endowment of pro-inflammatory cytokine TNF- $\alpha$ (-) $308 \mathrm{G}>$ A polymorphism to Parthenium hysterophorus induced air borne contact dermatitis in an Indian cohort. Int J Dermatol 2015; 54:179-84. 